\title{
A IATIIEPATICAL MODEL FOR ANALYSIS OF MOUNTAIN DRAINAGE BASINS
}

\author{
Maria Morandi Cecchi \\ I.E.I. of CNR Via S. Maria 46 Pisa
}

\section{Introduction}

To develop a mathematical model for analysis of mountain drainage basins is necessary to recall all concept of morphometry. This is done to be able to introduce, a quantization of geological concepts and to prepare a file of geological data able to give a complete description of the morphology and litology of the territory.

The method of the morphometical analysis are applied to the two foundamental aspects of the territory: the river branches and the river sides.

The topic of this paper is related to the hydrographyc basins considered as hollow regions of the lithosphere where the meteoric waters inflow and in different ways outflow to the final collector that discharge them into the sea or into a lake.

The study is mostly important when applied to the mountain basins that are of relative small area but play a fundamental role into the dynamics of the flow.

Infact every thing may happen in the environment of the mouth of a hydrological system of a certain amount of waters (such as rivers, torrents, etc.) and the behaviour of such sections is strictly tied to the general systematization of the totality of the related mountain basins, infact are exactly the mountain basins that may generate regular or unregular flows.

It is clear that the litology (the composition of the rocks) and the tectonics (the lay of the rocks) are very important factors to be taken into account in the study of the mountain drainage basins. The geological control of the mountain basins is therefore necessary to give a good interpretation of the data. The method proposed is the following: to use the morphometry to evaluate automatically a monodimensional model for the river branches in its drainage area. Such fnrmulation is based on statistics because only with an analysis of the recurrences of the phenomena observed and with an analysis of the data, it is possible to abtain feasible frequency laws. This method was proposed in [1] and is convenient to build a data file of the branches of the rivers and of the sides of the rivers. 


\section{The method proposed}

The key of the method is the hierarchisation of hydrographic basins having determined the mesh of the watersheds as preference road for the waters (rain of snow melting) to flow out.

The hierarchy defined is very simple, the first order is defined with those branches that do not receive any other branch, channels of the second order are defined those that are generated by the junction of two branches of the first order.

The third order is defined as the function of two branches of the second order, and so on. It is obvious that such ordering is a function of the topographic chard used. Infact the ordering is defined on the chards and the scale of such chards is 1:25.000 or 1:100.000 very important in this study are the anormalous inflows that appear when a branch of a certain order does not flows into the branch of the following order but instead flows into some branch of an other higher order.

Such anomalous cases are of fundamental importance to undestand the degree of systematization of a drainage basin.

Therefore the number of anomalous cases is evaluated for every order and the frequency is evaluated two. A parameter that is also evaluated is the ratio of the frequency over the hierarchical order.

If higher is the number of anomalous cases less settled is the basin itself. A great number of anomalous cases may be the cause of a messy and unforeseeable flow.

On the contrary a hierarchisation completely normal; i.e. Without anomalous branches, would give a perfectly regular flow.

To illustrate more deeply the ideas presented here see specific geological literature as in $[2][3][4][5][6][7][8][9][10][11][12][13][14][15]$.

\section{The monodimensional model of river branches.}

The water system mesh is analysized using the hierarchisation automatically by the computer, the watersheds mesh gives the boundary of the drainage area associated to every branch of river under consideration, the considered model is related to the surface waters and to the gathered waters neglecting instead the dispersion for infiltration into the soil and for evaporation. For an hydrographic basin is intended that area where each element of it col- 
lects and drains a certain amount of water that comes from the inner part of the basin itself.

An example is given of the torrent Branega in Liguria where either the monodimensional and the treeadimensional model is applied.

In fig. 1 the hierarchisation of the basin is shown and in fig. 2 all the drainage basin of every branch of the river is shown.

The length of every branch is been evaluated, an average was obtained for every order and also the ratio between the average length of an order and of the following order is obtained.

Summing the lenghts average of the preceeding order one obtain the average of the basin and from it also the ratio length are evaluated. All the value of the area of every channel are evaluated, the averages are calculated and summed to the drainage area of the preceeding orders that inflow into branches of that order.

Informations are also taken into account about the kind of development i.e. the problem of the erosion of the rocks in a certain drainage area. A classification is made of different kind of soil and different classes of soils are specified. The first class collects all kinds of soil were a free development is allowed.

In the second class are included all soils for which a partially obliged development is allowed but for which the erosion is impossible. In the third class are the soils for which the development is partially obliged but the erosion is possible.

In the fourth class the development is completely obliged.

The quantisation abtained permit the comparison of the behaviour of different types of drainage basins.

All the quantities evaluated have been recorded into a data file to optimize the allocation and the use of territory resources.

4. A three-dimensional model of the sides of drainage basins of rivers branches.

Such model gives the knowledge of the surfaces of drainage basins sides, and it is based on a triangular mesh. This mesh is made automatically using as a starting point a given axis in the direction Sud-North, every drainage area is subdivided into 16 triangle, all of these triangles have one vertex in the theoretical center of the drainage area. 
Automatically the surface and the planimetric area of the sides are evaluated and also the angles of the sides are evaluated. With the phisiographic aspects that are introduced in the way exposed, it is important to consider also the permeability of the soil and the information is given for the drainage basin of every branch.

A coefficient was introduced to measure the degree of permeability.

All these informations are obtained and elaborated and give a complete morphometric knowledge of the territory and this knowledge consitues the geological data file to be used if a control of the flow of water has to be made.

The control is intended mostly in consideration of problems of erosion and sedimentation.

\section{An optimization algorithm for forecast of erosion.}

A forecast of the behaviour of erosion and sedimentation is based on an algorithm of search of the preference path for erosion and of a measure of the possible erosion of every path.

One is looking for the path of maximum erosion such path will be chosen on the base of having maximum difference in height between initial and final node, minimum total lenght, the total lenght beeing obtained summing all the lenghts of each path from every sping point to the final point, the final point beeing either the mouth of the river or the point where the river goes into a lake etc. and if the river runs across a territory where in a certain measure erosion is possible.

Let consider the graph that it is possible to obtain by the computer using the informations in the data file, fig. 3 in the case of Branega, in an interval $[0, t]$ of the real line, a differential equation of the form:

$$
y(x, t)=f(y(x, t), e(x, t))
$$

it is considered where $y(x, t)$ is a function of state $e(x, t)$ is a control function, $f$ is a mapping.

Equation ( 1 ) describes a dynamics systems which where supplied with an initial state $y(x, 0)$ and a control input function e produces a function $y$.

$$
y(x, 0)=k(x)
$$




$$
G=\int_{0}^{t} u(y, e) d t
$$

and a finite number of terminal constraints

$$
f_{i}(y(t))=c_{i} \quad i=1,2, \ldots r
$$

$y(x, t)$ is a function that describes the sedimentation $e(x, t)$ is the erosion function of a particular path considered. The function $u$ and $f_{i}$ are assumed to possess continuous partial derivatives with respect to their arguments. The optimal control is then that of finding the pair of function $(y, e)$ maximising $\checkmark$ while satisfying the equilibrium condition between sedimentation and erosion and the initial and terminal conditions (2) and (3). The procedure applied is completely classical. In the special case of torrent Branega in Liguria the optimization method was applied and the numerical results indicate a path as the preference path for the maximum of possible erosion and the numerical answer give a numerical measure of a parameter of erosion that coincide reasonably with observations on the territory considered.

The method has also been applied to a more extended region: the region of Cornia in Toscana; in the following figures are indicated the drainage areas and the hierarchisation applied and corrisponding to the data file. The evaluations have been made in a modular way and connected to the collector part of the region. In this part the hierarchy has reached the order 9.

In fig. 4, 5, 6, 7 one may see the regions considered.

\section{REFERENCES}

[1] CECCHI MORANDI M., DEL GROSSO A., LIMONCELLI B., "Un'applicazione dell'Informatica alla Geologia: un modello monodimensionale per lo studio dei reticoli fluviali ed uno tridimensionale per lo studio dei versanti." (to appear)

[2] MONKHOUSE, "Dizionario di Geografia", Zanichelli, Bologna (1974). (Versione italiana di "Dictionary of Geography", second edtion, Edward Arnold Publishers, Ltd. 1970).

[3] TRTCART J. e CAILLEAUX A., "Traité de Géomorphologie, SEDES, Paris, Vol.1 (1965).

[4] PANIZZA M., "Elementi di Geomorfologia", Pitagora Ed., Bologna (1973).

[5] MORTON R.E., "Erasional development of streams and their drainage basins; hydrophysical approach to quantitative morphology". Geol. Soc. of America Bulletin, Vol. 56, New York (1945). 
[6] SCHUMM S.A., "Evolution of drainage systems and slopes in Badlands at Perth Amboy, New Jersey". Geol. Soc. of America Bulletin, Vol. 67, New York (1956).

[7] STRAHLER A.N., "Quantitative analysis of watershed geomorphology". Amer. Geophys. Union Trans., Vol. 38, Washington (1957).

[8] DEL GROSSO A., LIMONCELLI B., "Proposta di un criterio di raccolta di dati delle analisi geomorfiche dei reticoli fluviali finalizzata ad elaborazione automatica". Atti del III Convegno Nazionale di Studi sui Problemi della Geologia Applicata, Firenze (1973).

[9] SHREVE R.L.. "Statistical law of stream numbers". Journ. Geology, Vol. 74 Chicago (1966).

[10] AVENA G.C., GIULIANO G., "Considerazioni teorico-pratiche sulla applicazione dell'analisi geomorfica quantitativa ai reticoli fluviali". L'universo, a. 47, Vol. 2, Firenze (1967).

[11] AVENA G.C., GIULIÁNO G., LUPIA PALMIERI E., "Sulla valutazione quantitativa della gerarchizzazione ed evoluzione dei reticoli fluviali". Boll. Soc. Geol. It., Vol. 86, Roma (1967).

[12] LAMBE T.W., WHITMAN R.V., "Soil mechanics". John Wiley and Sons, New York (1969).

[13] BOULES J.E., "Foundation analysis and design". Mc Grow Hill. New York (1968).

[14] CASTANY G., "Traité pratique des eaux souteraines". Dounod, Paris.

[15] MELTON M.A., "Geometric properties of nature drainage systems and their representation in an E4 phase space". Journ. of Geology, Vol. 66, Chicago (1958). 


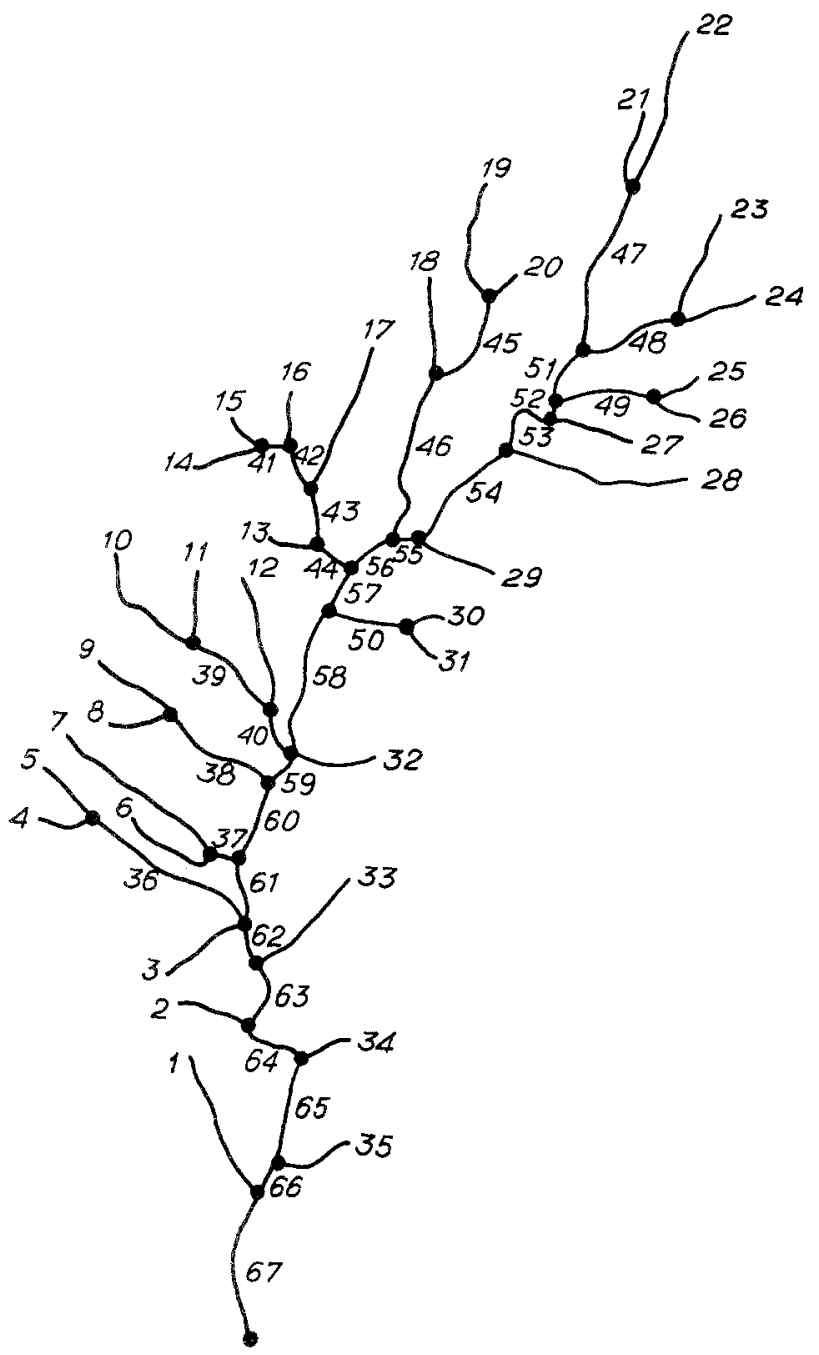

Fig. 1 


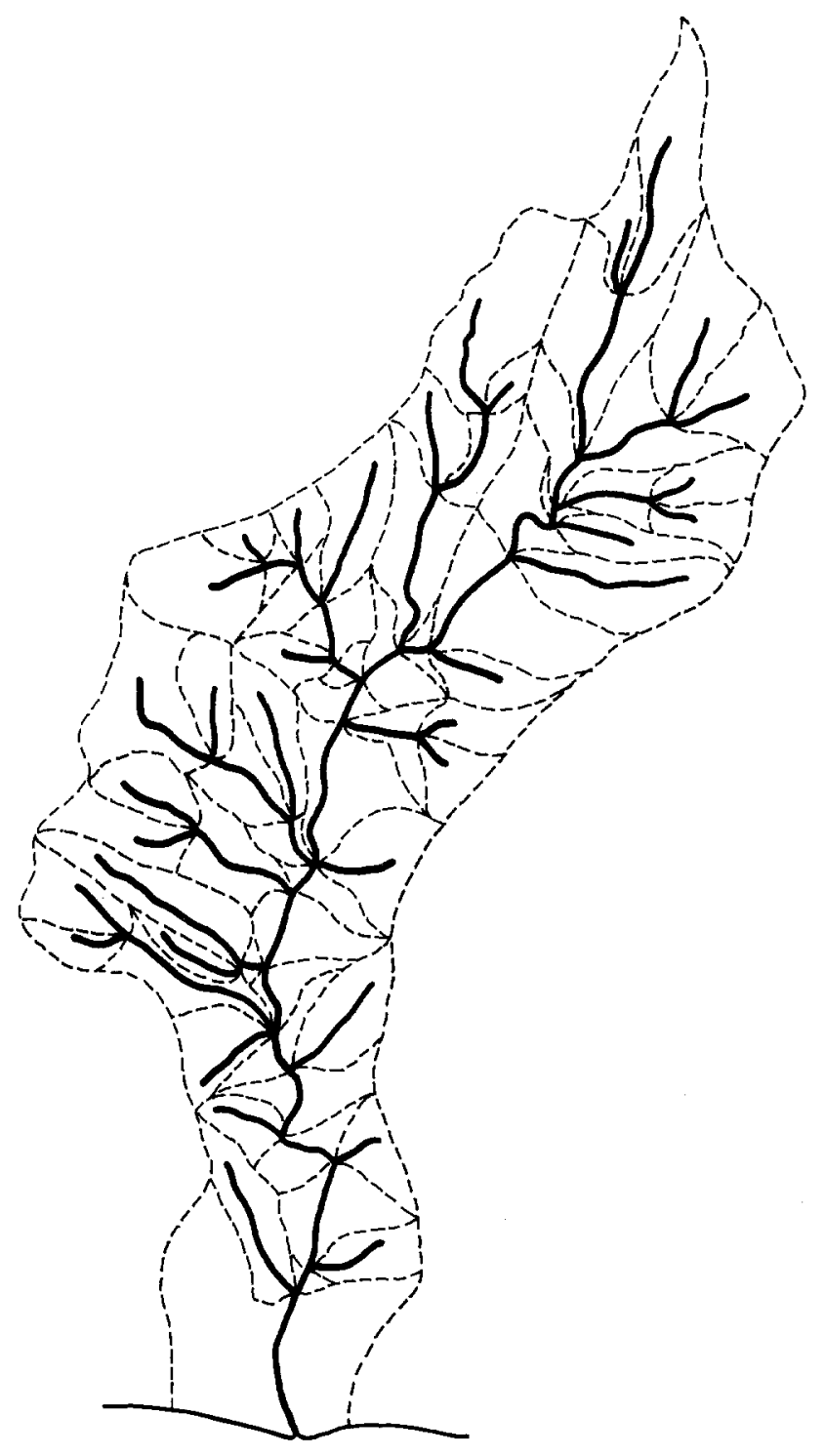

Fig.2 


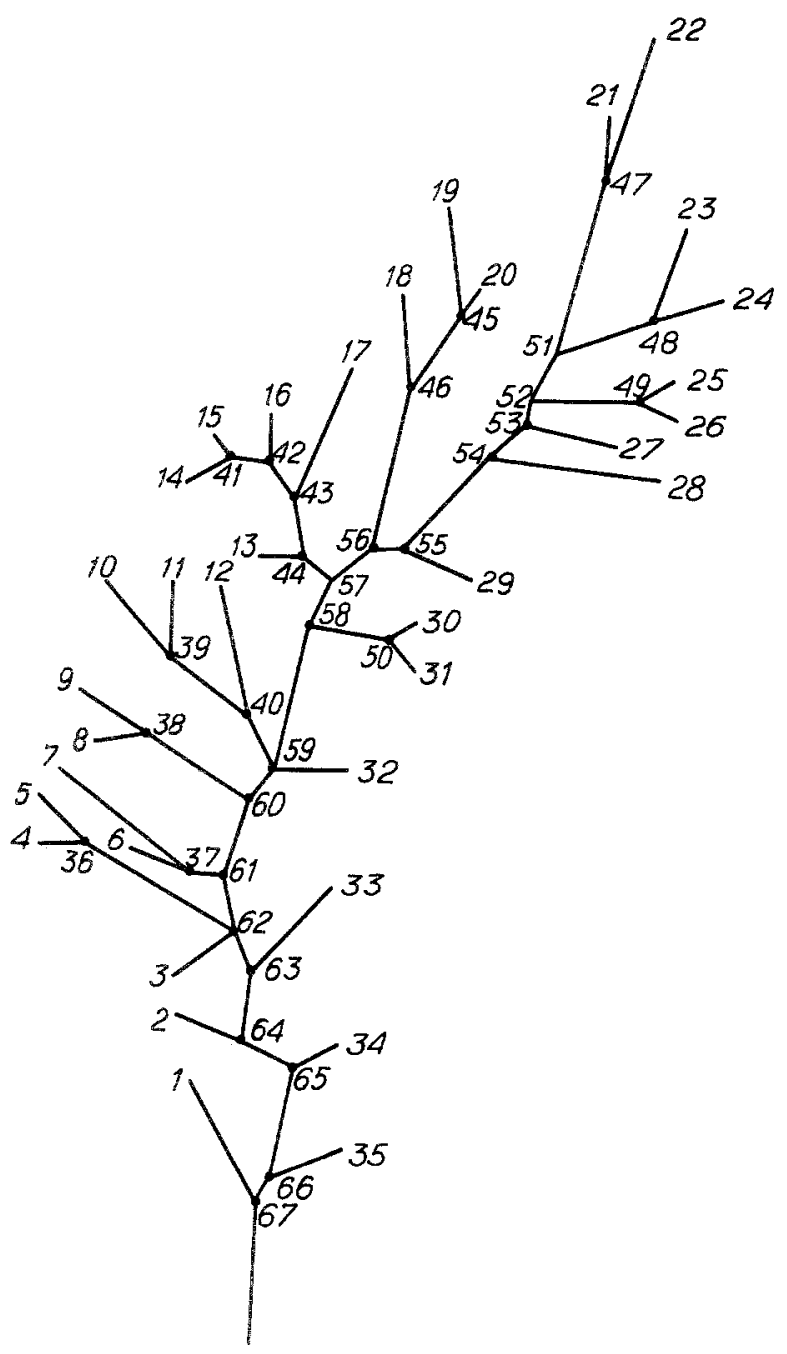

Fig. 3 
359

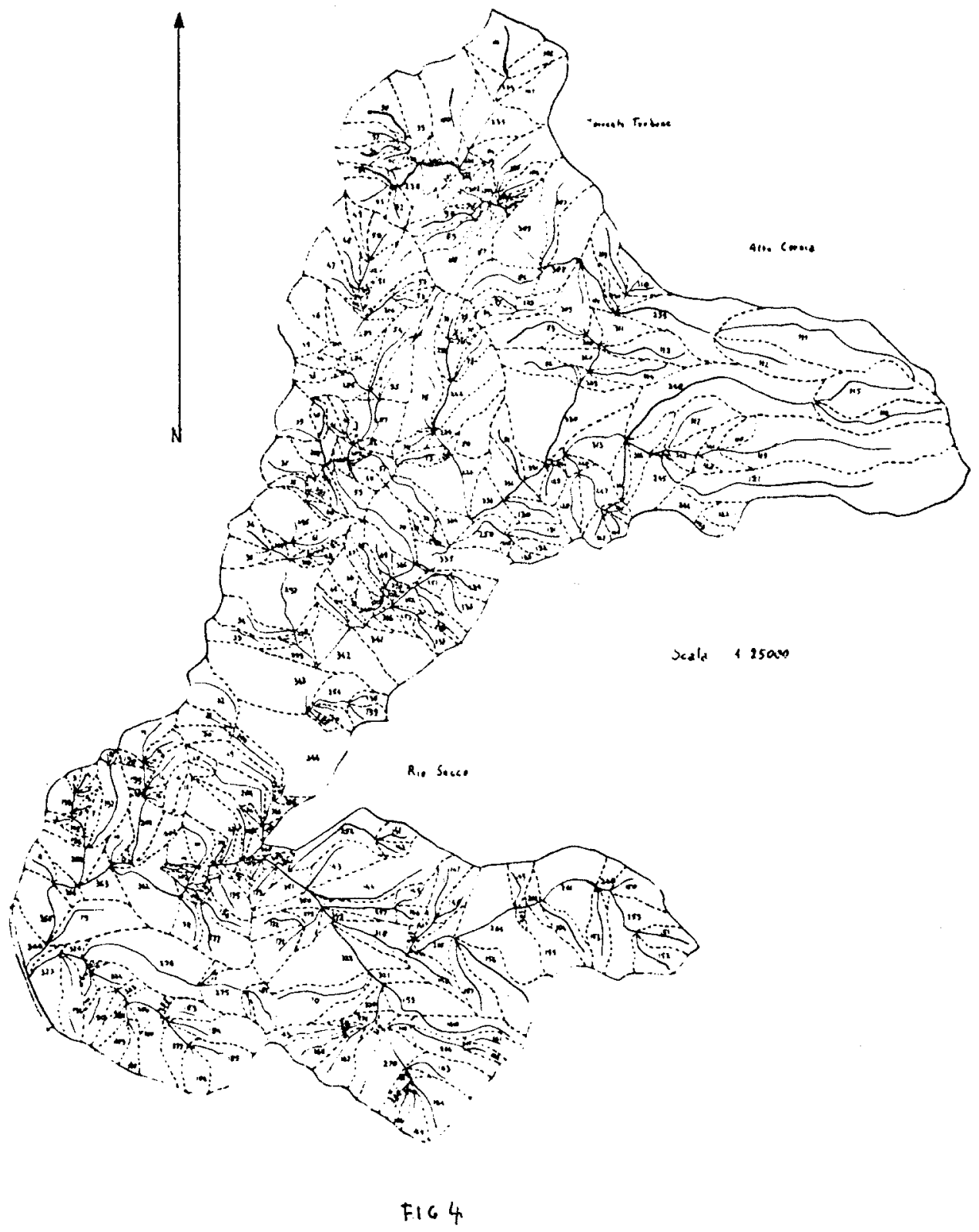




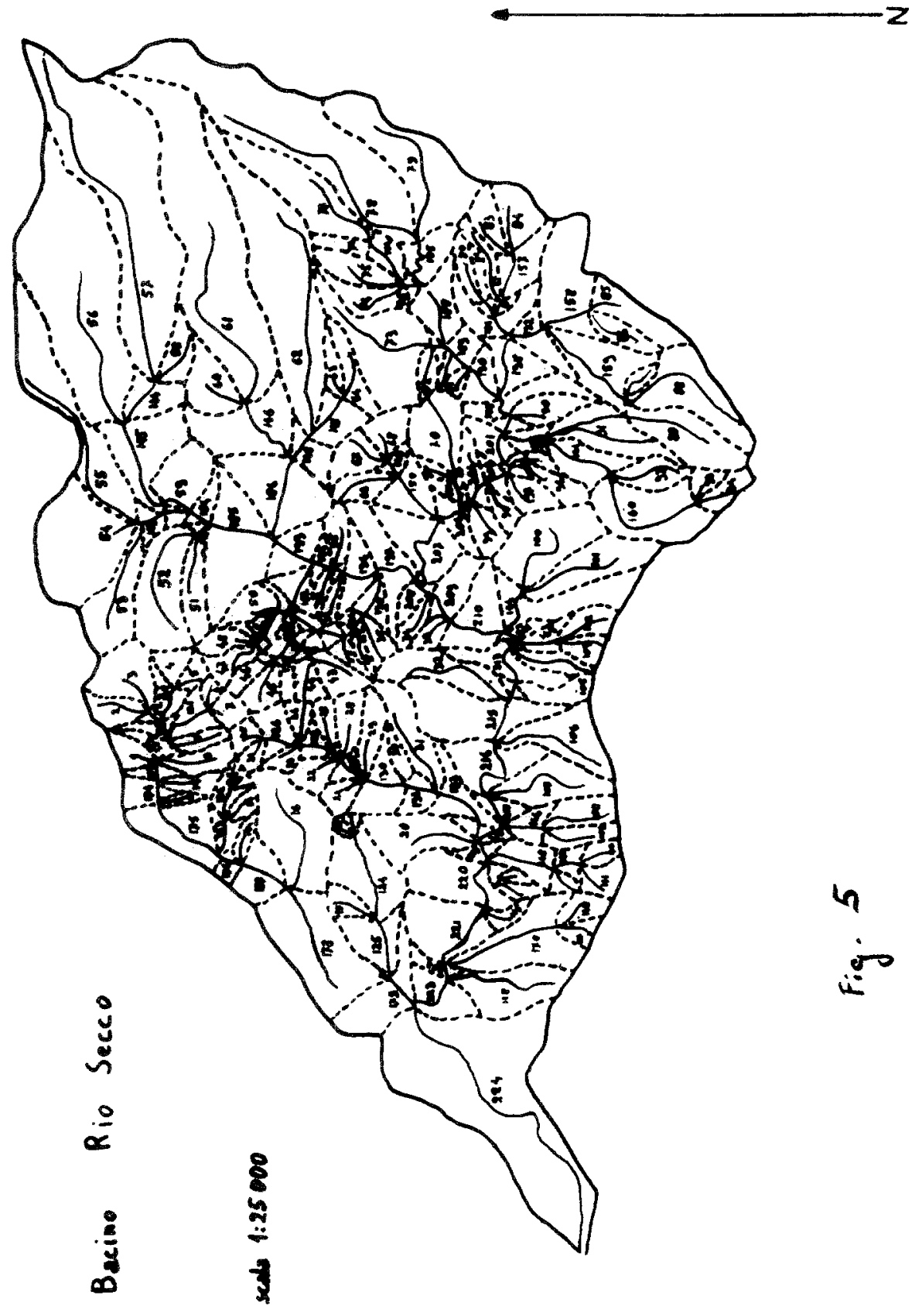




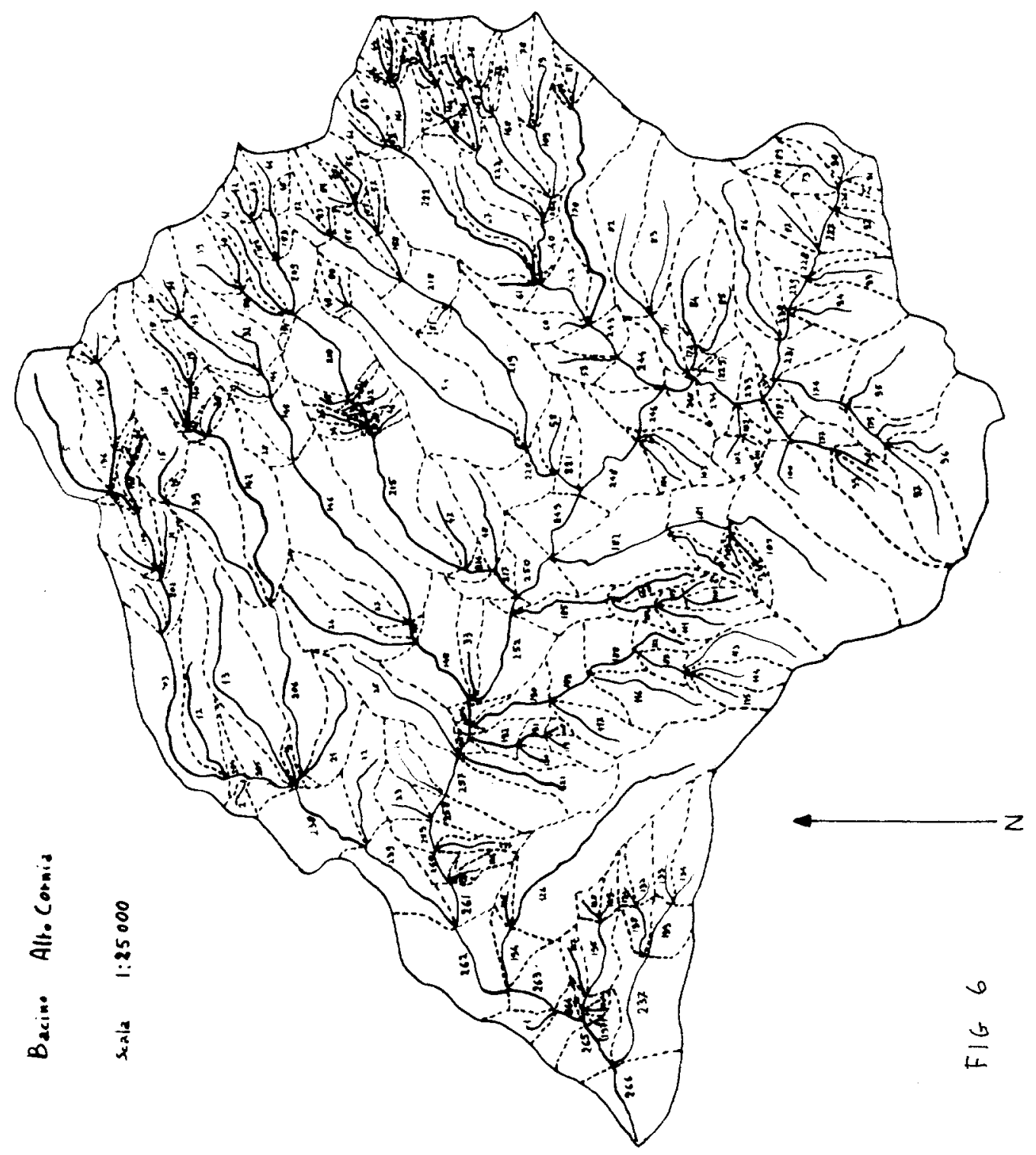




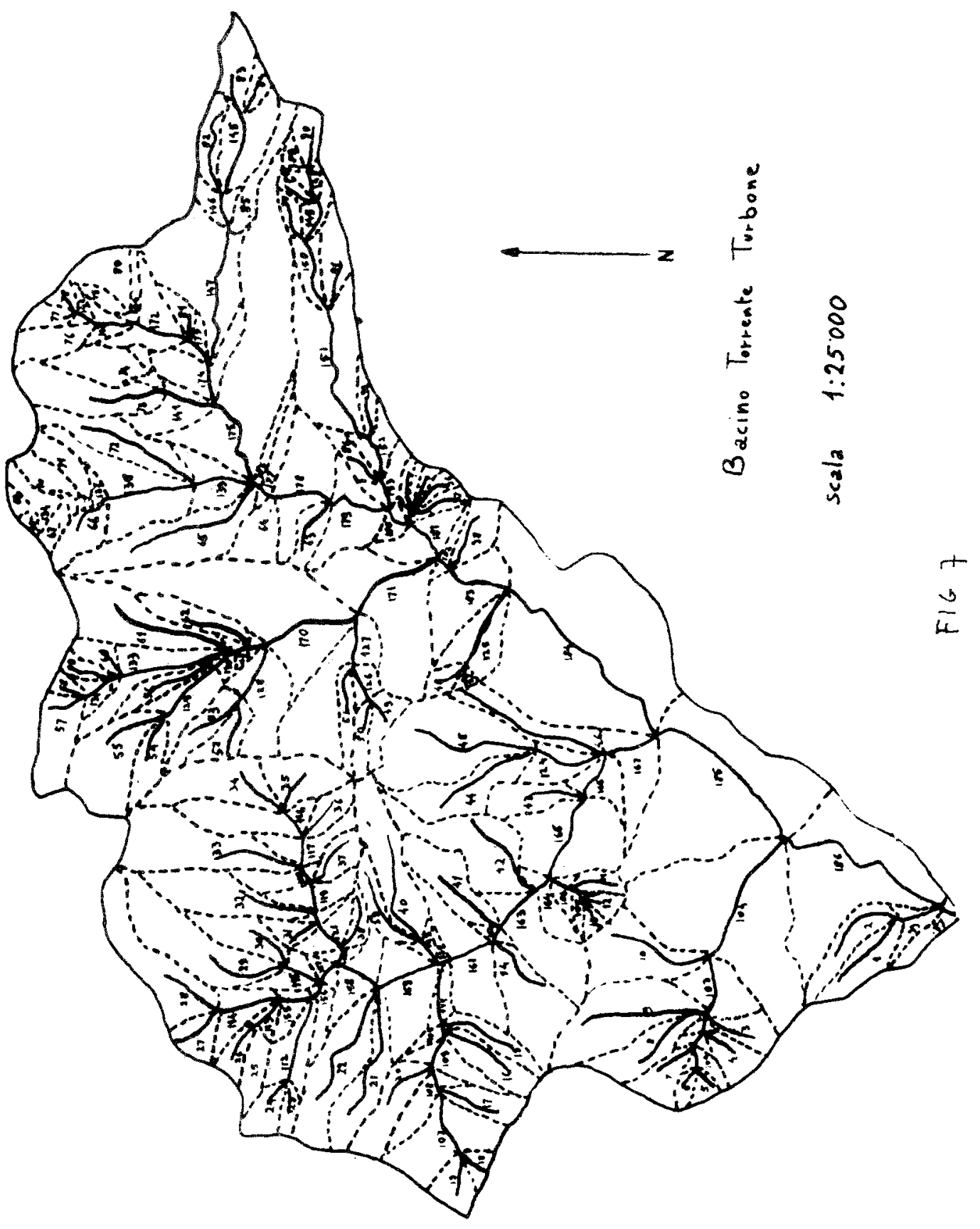

